\title{
The Dark Side of Internal Capital Markets: \\ Divisional Rent-Seeking and Inefficient Investment
}

David S. Scharfstein and Jeremy C. Stein

September 1999

\begin{abstract}
We develop a two-tiered agency model that shows how rent-seeking behavior on the part of division managers can subvert the workings of an internal capital market. By rent-seeking, division mangers can raise their bargaining power and extract greater overall compensation from the CEO. And because the CEO is herself an agent of outside investors, this extra compensation may take the form not of cash wages, but rather of preferential capital budgeting allocations. One interesting feature of our model is that it implies a kind of "socialism" in internal capital allocation, whereby weaker divisions get subsidized by stronger ones.
\end{abstract}

MIT Sloan School of Management and NBER. This paper is a completely overhauled version of our March 1997 NBER working paper (\#5969) with the same title. We have received research support from the National Science Foundation and the Finance Research Center at MIT. We are grateful to Charlie Hadlock, Oliver Hart, Laurie Hodrick, Bengt Holmström, Preston McAfee, Vik Nanda, Julio Rotemberg, René Stulz, Dimitri Vayanos, Luigi Zingales, Jeff Zwiebel, the referees and seminar participants at Columbia, Harvard, Indiana, the NBER, Boston University, Utah, Ohio State, Stanford, Stockholm, Yale, the ASSA meetings, and the New York Fed for helpful comments. Thanks also to Melissa Cunniffe and Svetlana Sussman for help in preparing the manuscript. 
In recent years, it has become almost axiomatic among researchers in finance and strategy that a policy of corporate diversification is typically value-reducing. A variety of empirical evidence lends support to this view. For example, diversified firms apparently trade at lower stock values than comparable portfolios of specialized firms. ${ }^{1}$ Moreover, during the 1980s corporate acquirors systematically dismantled diversified firms with the view that the divisions would be more efficiently run as stand-alones. ${ }^{2}$

While it may be clear to most observers that diversification can destroy value, it is much less clear exactly how it does so. One general theme in the literature is that the conglomerate form of organization somehow exacerbates the investment inefficiencies that arise from managerial agency problems. There are two basic ways that this could happen. First, if one believes that managers have a tendency to overinvest out of free cash flow (Jensen 1986, 1993), it might simply be that conglomerates give managers more resources to play with, and hence lead to more overinvestment. ${ }^{3}$ Alternatively, it may be that conglomerates do not on average have more free cash flow, but that their internal capital markets do a worse job of allocating a given amount of resources than would external capital markets i.e., they tend to engage in inefficient cross-subsidization, spending relatively too much in some divisions, and too little in others.

This latter hypothesis about inefficient cross-subsidization in internal capital markets has been much discussed. And recent evidence suggests that conglomerates do in fact engage in active resource reallocation, moving funds from one division to another. ${ }^{4}$ But, it is far from obvious that any such resource reallocation should be expected to be systematically inefficient, even in a standard agency context. Indeed, Stein (1997), building on Williamson (1975), makes exactly the reverse argument. He notes that even if CEOs derive private benefits from control, and hence have a tendency to engage in empire-building overinvestment, there is a presumption that, conditional on the level of investment, any reallocation of resources across divisions will be in the direction of increased efficiency. This is because the CEO's ability to appropriate private benefits should ultimately be roughly in line with the value of the enterprise as a whole. To put it simply, while agency-prone CEOs may want big empires, it also seems reasonable that, holding size fixed, they will want valuable empires. ${ }^{5}$ 
Of course, one can think of exceptions to this general tendency. For example, there may be "pet" projects that effectively generate disproportionately high private benefits for the CEO. ${ }^{6}$ Nonetheless, it remains hard to explain pervasive allocative inefficiencies in internal capital markets simply by appealing to agency problems at the level of the CEO. This is especially true to the extent that the associated cross-subsidies follow a consistent and predictable pattern across firms and industries.

In this regard, many observers have claimed that the cross-subsidies in internal capital markets often tend to be "socialist" in nature - i.e., strong divisions typically wind up subsidizing weak ones. ${ }^{7}$ Or said somewhat differently, one of the fundamental failings of the conglomerate form of organization seems to be its inability to put the weakest divisions in the firm on much-needed diets. Unless one is willing to assume that CEOs systematically derive more private benefits from weak divisions - which seems implausible — such a socialist pattern cannot be rationalized simply by appealing to agency problems at the CEO level.

This suggests that in order to develop a satisfactory theory of inefficient cross-subsidies in internal capital markets, one has to go a level deeper in the organization, and explicitly examine the incentives and behavior not only of the CEO, but also of the division managers. That is what we do in this paper. Specifically, we consider a setting where division managers have the ability to engage not only in productive work, but also in wasteful rent-seeking activities. The effect of such rent-seeking in our model is that it increases division managers' bargaining power when they negotiate a compensation package with the CEO. It turns out that under plausible conditions, rent-seeking is more of a problem with managers of weaker divisions. This is because the opportunity cost to such managers of taking time away from productive work to engage in rent-seeking is lower.

The rent-seeking behavior we model is in some respects similar to the influence activities studied by Meyer, Milgrom and Roberts (1992), and it has some of the same implications. Their model also predicts that such distortionary behavior is more of a problem in divisions with poor prospects, and like ours, it suggests that firms may often be better off divesting such divisions. But it is important to note that rent-seeking or influence activities at the level of division managers do not by themselves necessarily generate any inefficiencies in 
the allocation of investment spending. ${ }^{8}$ After all, even if the CEO has to in some sense "overcompensate" rent-seeking division managers, wouldn't it be more efficient for everybody involved if the extra compensation was in the form of cash? Why use directed investment spending as a means of compensation?

Thus while a model with just division-level rent-seeking may in some cases deliver socialist outcomes with respect to cash wages - i.e., managers of weak divisions receiving salaries that seem to be too high relative to those paid to managers of strong divisions something else must be added if we are to make predictions with respect to capital allocation. This is where the agency problem between the CEO and the outside capital market comes in. We show that although outside investors would prefer that any extra compensation paid to division managers be paid in cash rather than with distorted capital spending, they have no means to enforce this. For in our setup, the hiring and retention of division managers must be delegated to the CEO. And as an agent, the CEO may not be inclined to pay the division managers in the currency that outside investors would prefer. More precisely, we demonstrate that given the nature of the optimal financial contract between outside investors and the $\mathrm{CEO}$, the $\mathrm{CEO}$ views it as less personally costly to distort investment in favor of those divisions whose managers require extra compensation, thereby conserving on cash payments to these managers.

Overall then, the primary novelty of this paper is to build a model with two layers of agency that can speak directly to the question of how some division managers in a conglomerate are able to extract excessively large capital allocations from the CEO. ${ }^{9}$ In addition to providing a theoretical rationale for the existence of inefficient cross-subsidies in internal capital markets, the model also enables us to make fairly precise predictions about both the direction of such cross-subsidies, as well as the circumstances under which they are most likely to be acute. For example, one of our principal results is that large socialist-type inefficiencies are especially likely to arise when there is a great deal of divergence in the strength of the divisions, and when the CEO has low-powered incentives.

Our two-tiered agency approach distinguishes us from another line of work that has also examined the question of why managers may be compensated with extra capital rather than 
cash. In these other papers, the party making the compensation decision is the principal (as opposed to the CEO, who is an agent in our set-up), so that it is actually efficient, in some constrained sense, to pay with capital. Rotemberg (1993) is an example. In his model, managers are rewarded with the right to make irreversible investment decisions, because this is a way for the principal to precommit not to renege on a long-term deal. ${ }^{10}$ Similarly, in Rajan, Servaes, and Zingales (2000), the principal optimally tilts the capital budget towards the weaker division in a firm, because this makes the weaker division more behave more cooperatively in joint production with other divisions. ${ }^{11}$ Thus, what is relatively unique about our model is that, by incorporating two levels of agency, we not only capture divisional rent-seeking behavior, but also the idea that the allocation of investment by the CEO reflects her own misaligned incentives and thus can be grossly inefficient from the perspective of outside investors.

The remainder of the paper is organized as follows. We develop the basic model in Section I, and consider some extensions and variations in Section II. Section III discusses several recent empirical papers that speak directly to the model's central predictions. Section IV concludes.

\section{The Model}

\section{A. Overview}

Our model considers a firm operating with two divisions and features three basic agents: division managers, a CEO, and outside investors. Within each division, there are both assets already in place, and new investment opportunities. Both division managers and the CEO derive private benefits from the assets under their purview. Thus the manager of a division gets private benefits from the assets of his division only, while the CEO gets private benefits from the assets of all divisions.

The CEO plays two important roles. First, she has the authority to allocate new investment across divisions. Second, she is charged with identifying, hiring, and retaining the division managers. As part of this second job, she has to negotiate with the division managers the terms of their employment — i.e., set their compensation. We explain in 
more detail below why these two jobs have to be delegated to the CEO, and cannot be accomplished by outside investors.

Much of the focus of our analysis is on how the CEO chooses to compensate division managers - whether she pays them in cash or with an inefficiently large share of the capital budget. However, to facilitate the exposition of the model, we begin by assuming that investment is allocated efficiently across the two divisions, and that any further rewards to division managers are paid in cash. In this setting, we analyze how the magnitude of the cash wage depends on both a division's productivity and the manager's rent-seeking behavior. Next, we describe the contracting environment between the CEO and investors, and show that given the nature of the optimal financial contract, there may be incentives for the $\mathrm{CEO}$, acting as an agent, to substitute capital expenditures for cash in the division manager's compensation.

\section{B. Production and Rent-Seeking When CEO Bargains With Cash Only}

There are two periods, 1 and 2. At time 1, the CEO hires a new manager for each division, to work with assets that are already in place. The wages of these new managers at time 1 are normalized to zero. The output of division $i$ at time 1 is $\theta_{i} f\left(e_{i}\right)$, where $\theta_{i}$ is a measure of the productivity of the assets in place, $e_{i}$ is the productive effort of the division manager, and $f($.$) is an increasing concave function. The output is fully and costlessly$ verifiable, and hence can be assigned to outside investors. In addition to this verifiable output, there are also non-contractible private benefits. In particular, division manager $i$ reaps a private benefit of $\gamma \theta_{i} f\left(e_{i}\right)$ from his own division, while the CEO gets a private benefit of $\phi \theta_{i} f\left(e_{i}\right)$ from each of the two divisions. These private benefits can be thought of in any number of ways: the usual perks, psychic benefits from empire building, etc. They are assumed to be small relative to the verifiable output - i.e., $\gamma$ and $\phi$ are both much less than one. This is in contrast to many recent models of financial contracting in which managers can "steal" a large share of the cashflows produced by operating assets. ${ }^{12}$ What matters for our purposes is that both division managers and the CEO care to some degree about the total amount of output from the assets under their span of control. 
At time 2, the old assets in place are fully depreciated, and there is a second round of production with newly invested capital. If the original division manager from time 1 remains on the job, the output of division $i$ at time 2 is $\theta_{i} k\left(I_{i}\right)$, where $I_{i}$ is the new investment in division $i$, and $k($.$) is an increasing concave function, with k^{\prime}(0)=\infty$. However, if the original division manager quits, and has to be replaced, output is reduced. The interpretation is that by time 2 , the original division manager has acquired some specific human capital, which makes him particularly valuable. This in turn means that the division manager may be able to bargain with the CEO for increased compensation at time 2. In any case, the CEO continues to get private benefits equal to $\phi$ times the output of each division, and the division manager continues to get private benefits equal to $\gamma$ times the output of his own division.

One of our key premises is that the division manager anticipates the time-2 bargaining ex ante, at time 1, and may take steps to enhance his negotiating position. This is what we mean by "rent-seeking": rather than spending all his time on productive effort $e_{i}$ at time 1 , division manager $i$ may spend $r_{i}$ on activity that is not directly productive, but that may enable him to extract more from the CEO when they negotiate at time 2. The division manager is subject to an overall time constraint that $e_{i}+r_{i}=h$. The allocation of effort is non-contractible, so that there is no way to directly force a division manager to spend his time in the right way.

We have examined two different formulations of rent-seeking. In the first, which we call "resumé-polishing", the rent-seeking effort $r_{i}$ goes to improving the division manager's outside option. The interpretation here is that the division manager spends too much time increasing his external visibility, perhaps attending industry conventions, accepting needless speaking engagements, and the like. Thus at time 2, the division manager has an outside option given by $g\left(r_{i}\right)$, where $g($.$) is an increasing concave function, with g(0)=0$. We further assume that if the division manager quits at time 2 and a new manager is brought on, output falls by a fixed amount $X$, to $\theta_{i} k\left(I_{i}\right)-X$.

In the second variant, which we term "scorched earth", the rent-seeking effort $r_{i}$ goes to making it harder for any successor to the division manager to take over the job. One might interpret $r_{i}$ in this context as time spent creating excessively opaque internal accounting 
systems, hiding other information, and so forth. ${ }^{13}$ In this case, the old manager's outside option remains at zero, but if a new manager comes in to run the division at time 2, output falls to $\theta_{i} k\left(I_{i}\right)-g\left(r_{i}\right)$. Note that in both variations, it is important that the old manager be somewhat entrenched at time 2 , in the sense of being more productive than any potential replacement. However, with resumé-polishing the degree of entrenchment is a constant given by $X$, while with scorched earth the degree of entrenchment depends on $r_{i}$. The two variations give broadly similar results, but the former is easier to work with. ${ }^{14}$ So to streamline the exposition, we focus on the resumé-polishing formulation in what follows.

To see how the model works with resumé-polishing, let us begin by assuming that it is time 2 , and that some non-zero effort $r_{i}$ has already been devoted to this form of rent-seeking. Therefore, the division manager now has an outside option of $g\left(r_{i}\right) .{ }^{15}$ Moreover, if he leaves, output falls by $X$. Now consider the respective bargaining positions of the division manager and the CEO. If the division manager quits at time 2 , he goes to his outside option and gets $g\left(r_{i}\right)$. If he stays, he gets utility of $\gamma \theta_{i} k\left(I_{i}\right)+w_{i}$, where $w_{i}$ is the cash wage (if any) agreed to by the CEO. For simplicity, we further assume that: i) the CEO has all the bargaining power at time 2 - i.e., she can make a take-it-or-leave-it offer to the division manager; and ii) $\phi X>g\left(r_{i}\right)$, for any value of $r_{i}$. The former assumption is not critical; as long as the CEO has some bargaining power at the time 2 , the division manager cares about his outside option $g\left(r_{i}\right)$, which is the important feature of the model. The latter assumption ensures that the CEO has enough of a stake in output that she always deems it privately efficient to retain the division manager, even if the cash wage $w_{i}$ has to come out of her own pocket. ${ }^{16}$

For the moment, we explore a benchmark scenario where the CEO is constrained to allocate investment efficiently across the two divisions, so that $I_{i}=I_{i}^{*}$, as given by: ${ }^{17}$

$$
\theta_{1} k^{\prime}\left(I_{1}^{*}\right)=\theta_{2} k^{\prime}\left(I_{2}^{*}\right)
$$

Moreover, we assume that the CEO also has enough wealth to pay any cash wages. In this setting, the CEO always rehires the division manager at time 2, and faces the following "retention constraint":

$$
w_{i}+\gamma \theta_{i} k\left(I_{i}^{*}\right) \geq g\left(r_{i}\right)
$$


In words, the CEO simply has to promise the division manager more total utility than he would get if he left. Note that the labor contract implied in this discussion is an easily implementable one. All that we require is that a court be able to verify: i) whether the division manager was in fact employed by the firm at time 2; and ii) whether the promised cash wage was paid. ${ }^{18}$

The first observation about the retention constraint is that it may be slack at the efficient level of investment, $I_{i}^{*}$. If division $i$ is very productive (i.e., has a high value of $\theta_{i}$ ) and is therefore doing a lot of investing at the efficient level, the division manager gets more than his outside option in utility even without a cash wage, so the CEO can set $w_{i}=0$. On the other hand, if the division has a low value of $\theta_{i}$, it is more likely that the CEO has to pay a positive cash wage to keep the manager at time 2 .

Now let us back up and consider the division manager's decision of how to divide his time between productive effort $e_{i}$ and rent-seeking $r_{i}$. If the manager rent-seeks, his time-1 private benefits fall by $\gamma \theta_{i}\left[f(h)-f\left(h-r_{i}\right)\right]$ because of the reduced time-1 output. However, his time-2 outside option rises by $g\left(r_{i}\right)$. If $g\left(r_{i}\right)$ is greater than $\gamma \theta k\left(I_{i}^{*}\right)$ - so that the retention constraint is violated when the wage is zero - then the CEO must pay a wage of $g\left(r_{i}\right)-\gamma \theta_{i} k\left(I_{i}^{*}\right)$ to keep the manager. Thus, for a given $r_{i}$ the manager rent-seeks provided the period-2 gain in wage compensation exceeds the loss in period-0 private benefits:

$$
g\left(r_{i}\right)>\gamma \theta_{i}\left[k\left(I_{i}^{*}\right)+f(h)-f\left(h-r_{i}\right)\right]
$$

If there is an $r_{i}$ that satisfies this "rent-seeking condition", we know that there is at least some rent-seeking in equilibrium. ${ }^{19}$ Just how much, $r_{i}^{*}$, is determined by equating the marginal gain in time- 2 compensation and the marginal loss in time- 1 private benefits:

$$
g^{\prime}\left(r_{i}^{*}\right)=\gamma \theta_{i} f^{\prime}\left(h-r_{i}^{*}\right)
$$

Note, however, that if at $r_{i}^{*}$ the rent-seeking condition:

$$
g\left(r_{i}^{*}\right)>\gamma \theta_{i}\left[k\left(I_{i}^{*}\right)+f(h)-f\left(h-r_{i}^{*}\right)\right]
$$

is not met, then the manager does not actually rent-seek. What this means is that the equilibrium level of rent-seeking, $\hat{r}_{i}$, is given by the following: 


$$
\hat{r}_{i}=\left\{\begin{array}{rc}
r_{i}^{*} & \text { if } g\left(r_{i}^{*}\right)>\gamma \theta_{i}\left[k\left(I_{i}^{*}\right)+\Delta f_{i}\right] \\
0 & \text { otherwise }
\end{array}\right.
$$

where, for shorthand, we define $\Delta f_{i} \equiv f(h)-f\left(h-r_{i}^{*}\right)$.

The main implication of this analysis is that managers of weaker divisions (those with lower values of $\theta_{i}$ ) do more rent-seeking. More precisely, we can distinguish two regions. In the first, when $\theta_{i}$ is below some cutoff (call it $\bar{\theta}$ ) the rent-seeking condition (5) is satisfied, so managers choose to actively rent-seek. In this region the level of rent-seeking increases as $\theta_{i}$ falls, because managers in charge of less productive assets at time 1 have a lower opportunity cost of taking time away from productive effort. This is reflected in the first-order condition (4). In the second region, for values of $\theta_{i}$ above $\bar{\theta}$, managers do not rent-seek at all: the rent-seeking condition (5) is not satisfied. At these higher levels of $\theta_{i}$ there is no incentive to rent-seek, both because of the large loss in time-1 private benefits that this would entail, and because the time- 2 private benefits, $\gamma \theta_{i} k\left(I_{i}^{*}\right)$ are already high.

Correspondingly, the cash wage is greater for managers in low- $\theta$ divisions. In the rentseeking region $\left(\theta_{i}<\bar{\theta}\right), w_{i}=g\left(r_{i}^{*}\right)-\gamma \theta_{i} k\left(I_{i}^{*}\right)$. Since managers in low- $\theta$ divisions rent-seek more, and derive less private benefits from time-2 investment, they must receive higher wages to get them to stay. In very high- $\theta$ divisions $\left(\theta_{i}>\bar{\theta}\right)$, managers do not rent-seek at all and so do not need to be compensated further to be retained in the firm. ${ }^{20}$

Before proceeding, it is worthwhile to interpret the results to this point. Recall that we have not yet introduced the possibility that the CEO attempts to compensate division managers with investment levels above the efficient values of $I_{i}^{*}$; this comes shortly. For the time being, cash wages are the only currency. In this context, $w_{i}$ is a complete measure of both: i) the magnitude of the rent-seeking problem; and ii) how much "extra" (above and beyond the efficient level of investment) the CEO has to give division managers to get them to stay on. So what we have learned is that the CEO always has a tougher problem with the managers of weak (low- $\theta$ ) divisions. This is true because of two distinct effects. First, there is what might be called a time-2 "satisfaction effect": efficiency dictates that high- $\theta$ division managers are naturally allocated more capital at time 2 ; this means that their utility 
from staying on is higher, so that the benefits from rent-seeking are low. Second, there is a time-1 "opportunity-cost-of-rent-seeking effect": even if they do engage in rent-seeking, high- $\theta$ division managers will spend less of their time on it, because they view it as more costly to take time away from productive activity.

It can be argued that our model is missing a countervailing ingredient. Specifically, one might posit that for a variety of reasons, a division manager working in a better industry might find it easier to generate outside options. For example, one might write the outside option as $\left(1+\delta \theta_{i}\right) g\left(r_{i}\right)$ for some $\delta>0$, which corresponds to the marginal productivity of resumé-polishing being greater in high- $\theta$ industries. If $\delta$ is sufficiently large, this can lead to a situation where, if he chooses to rent-seek, the manager of a stronger division obtains a higher outside option - i.e., for an optimally chosen $r_{i}^{*},\left(1+\delta \theta_{i}\right) g\left(r_{i}^{*}\right)$ can be increasing rather than decreasing in $\theta_{i}$.

However, it is important to recognize that this countervailing effect need not overturn our central result. Even if $\left(1+\delta \theta_{i}\right) g\left(r_{i}^{*}\right)$ increases with $\theta_{i}$, it does not follow that the $\underline{\text { equilibrium outside option, }}\left(1+\delta \theta_{i}\right) g\left(\hat{r}_{i}\right)$, increases with $\theta_{i}$. This is because of the strong "satisfaction effect" that we have identified. In equilibrium, a manager of a high- $\theta$ division may still be more likely to have $\hat{r}_{i}=0$, as is apparent from equation (6). In words, the high- $\theta$ manager is getting so much utility from running a profitable division with a large capital budget that he is no threat to leave the firm, and, therefore, his resumé-polishing abilities are irrelevant. Of course, it is always possible to reverse our conclusions by raising $\delta$ far enough, but this line of reasoning suggests that they are somewhat robust.

Moreover, as noted above, the basic notion that managers of weak divisions can cause more problems for the CEO is not unique to this model. We are more interested in using it as a point of departure. In particular, now that we know that the CEO has to give more extra compensation to low- $\theta$ division managers, we can turn to our central question: what form does this extra compensation take? Is it paid in cash, or with an inefficiently high share of the capital budget? To answer this question, we have to be clearer about the nature of the agency relationship between the CEO and outside investors. 


\section{CEO-Level Agency and the Form of Division-Manager Compensation}

To create an interesting agency problem at the CEO level, we assume that the CEO has no wealth of her own. The first implication of this assumption is that the financing for any new time- 2 investment of $I_{1}+I_{2}$ must come from outside investors. The form of the financial contract is very simple. Outside investors have two forms of contractual protection to ensure that they earn a return on their investment in physical assets. First, they can specify $\bar{I}$, the amount of their investment in the firm as a whole which must be converted into physical capital. That is, the act of converting cash into physical capital is verifiable; this is a standard assumption. Second, as we have already noted, once the capital is put into place, it generates future cashflows which are also verifiable, and which outside investors can directly appropriate. Thus on the whole, funding which is put up for capital investment is relatively well-protected in this model - aside from potentially small amounts of perks taken by the CEO and division managers, outside investors recoup everything else coming from physical capital. ${ }^{21}$

One thing that outside investors cannot do is specify how the total firm-wide capital budget of $\bar{I}$ gets split up across divisions. This control right is assumed to reside with the CEO. We take this delegation of capital-allocation authority to the CEO to be a defining characteristic of integration. ${ }^{22}$ Of course, to the extent that our model generates large inefficiencies, this begs the question of why there should be integration in the first place; i.e., why shouldn't the firm be broken up? It is important to be clear that our aim here is not to provide a complete equilibrium model of the costs and benefits of integration, but rather just to assume that integration has taken place for some exogenous reason, and to explore some of its potentially dysfunctional consequences. ${ }^{23}$ Thus we are perfectly comfortable with the view that some of the largest inefficiencies implied by the model may not survive in the long run because there will be pressure to break up the firm. Indeed, we like to think that the model has predictive content for the circumstances in which breakups are most likely to occur, a point which we take up explicitly in Section II.B below.

The second key aspect of the agency problem between the CEO and outside investors is that the hiring and compensation of division managers must be delegated to the CEO. 
That is, the outside investors cannot contract directly with division managers. ${ }^{24}$ There are a number of ways to motivate this feature. For example, one might assume that all contracting between the $\mathrm{CEO}$ and outside investors takes place at some initial chartering date (denoted "time 0") before any specific candidates for the division manager jobs have been identified by the CEO. After this initial round of contracting, there is no further scope for outside investors to get re-involved; this could be justified by appealing to the notion that the outside investors are a diffuse group, and cannot easily coordinate in such a way as to rewrite contracts on an ongoing basis. ${ }^{25}$

Given that they cannot write contracts with the division managers themselves, it may be optimal for outside investors to give the CEO additional funds that are not contractually earmarked for physical investment. The potential benefit of doing so is that the CEO may use these other funds to compensate division managers with cash wages rather than with distorted capital budgets. Thus in addition to the capital budget of $\bar{I}$, we allow for the possibility that there is a total "operating budget" of $\bar{W}$.

As will become clear, our main results are driven by assuming that it is contractually difficult for outside investors to fully protect the operating budget from abuse by the CEO. Or said differently, we need to assume that if the CEO does not turn the operating budget over to division managers, she can to some degree spend it on herself. To illustrate the ideas most starkly, we begin with an extreme case where the operating budget is totally discretionary for the CEO. That is, outside investors give $\bar{W}$ to the CEO, and anything that she does not spend on wages for the division managers, she can directly divert to herself.

Obviously, this stark assumption about the CEO's ability to take home the operating budget is not intended to be realistic. What we have in mind is that, in a richer model, the operating budget would have to be used to cover a wide range of expenditures other than those verifiable outlays on physical capital that are specified in the capital budget. In addition to division-manager wages, these would include money spent on advertizing, administration, travel, etc. To the extent that the CEO holds down division-manager wages, she can spend more of the operating budget on things that raise her utility (e.g., excess travel). ${ }^{26}$ Our simple formulation corresponds to an extreme case where these discretionary 
expenditures raise the CEO's utility dollar-for-dollar; however, this is not at all necessary for our results.

While the notion that the CEO can divert a portion of the operating budget to herself does not strike us as unreasonable - indeed, it is a standard assumption in the agency literature - it is nevertheless not the only way to tell the story. Ultimately, all we really need is some motivation for the CEO to care about conserving on cash wage payments to division managers. Another way to derive this feature is to assume that the CEO has profitlinked incentive compensation. Then, by holding down wages, she boosts profits and - even if these excess profits are returned to shareholders rather than diverted - also raises her compensation. Somewhat more subtly, the same effect can arise if the CEO has stock in the firm, and she wants to raise reported profits in order to pump up the near-term stock price, as in the signal-jamming model of Stein (1989). We sketch out this alternative formulation of the model in more detail in Section II.A below.

In order to analyze the properties of model, we now proceed as follows. First, we begin by treating the size of the capital budget $\bar{I}$ as a fixed parameter, and assuming that the operating budget $\bar{W}$ is sufficiently large that the CEO is unconstrained in setting cash wages. Once we have solved the model this way, we can back up and endogenize $\bar{I}$, as well as check whether this approach to setting $\bar{W}$ is optimal from the perspective of outside investors.

The retention constraints faced by the CEO are almost identical to before. In particular, they are now given by:

$$
w_{i}+\gamma \theta_{i} k\left(I_{i}\right) \geq g\left(r_{i}\right)
$$

The only difference is that now we allow for the possibility that $I_{i}$ differs from $I_{i}^{*}$. In other words, the CEO may meet a binding constraint either by using a cash wage or by raising investment above the efficient level.

The CEO seeks to maximize her utility, subject to these constraints. ${ }^{27} \mathrm{CEO}$ utility at time 2 is given by:

$$
\phi \theta_{1} k\left(I_{1}\right)-w_{1}+\phi \theta_{2} k\left(I_{2}\right)-w_{2}
$$


In words, expression (8) says that the CEO cares about two things. On the one hand, she cares about allocating investment efficiently - because she gets more private benefits with higher output — but she only puts a fractional weight of $\phi$ on this objective. On the other hand, she also wishes to minimize cash wages, because, according to our strong assumption, any cash wages ultimately come dollar-for-dollar out of her pocket. Note that if the CEO instead acts benevolently on behalf of outside investors, the objective function would be of the same form as above, except that we would set $\phi=1$.

In this version of the model, in which the investment allocation can vary, each division manager's rent-seeking decision is more complex because it may now depend on the other division manager's rent-seeking strategy. In fact, rent-seeking choices may be strategic complements; either manager may have more incentive to rent-seek if the other manager also rent-seeks.

To understand why, recall that if a given manager $i$ rent-seeks, he gets $g\left(r_{i}^{*}\right)$ at time 2 and loses $\Delta f_{i}$ in time-1 private benefits. This is the case no matter what the other manager $j$ does. However, if manager $i$ does not rent-seek, his time-2 private benefits depend critically on manager $j$ 's rent-seeking activity. His utility at time 2 in this case comes only from what the CEO decides to allocate in capital to his division $i$; since he has no outside option there is no reason for the CEO to pay him a wage. And his capital allocation is determined in part by the desire of the CEO to meet manager $j$ 's retention constraint. Thus, manager $i$ 's time-2 private benefits can be written as $\gamma \theta_{i} I_{i}\left(r_{j}\right)$, where $I_{i}\left(r_{j}\right)$ denotes the investment allocation to $i$ if $i$ does not rent-seek and the other manager, $j$, rent-seeks at level $r_{j}$. This implies that manager $i$ rent-seeks if:

$$
g\left(r_{i}^{*}\right)>\gamma \theta_{i}\left[k\left(I_{i}\left(r_{j}\right)\right)+\Delta f_{i}\right]
$$

As will become clear, the capital allocation to $i$ tends to be reduced below the efficient level if only $j$ actively rent-seeks: $I_{i}\left(r_{j}^{*}\right)<I_{i}^{*}$. It follows that $i$ 's incentive to rent-seek can be greater if $j$ rent-seeks - this is the sense in which rent-seeking activities can be strategic complements. Note that this is the case even though manager $j$ 's rent-seeking does not directly reduce the rents available to manager $i$. 
Now let us make the following further definitions. We say that:

$$
\begin{gathered}
\theta_{i} \text { is "low" if } g\left(r_{i}^{*}\right)>\gamma \theta_{i}\left[k\left(I_{i}^{*}\right)+\Delta f_{i}\right] \\
\theta_{i} \text { is "medium" if } \gamma \theta_{i}\left[k\left(I_{i}^{*}\right)+\Delta f_{i}\right] \geq g\left(r_{i}^{*}\right)>\gamma \theta_{i}\left[k\left(I_{i}\left(r_{j}^{*}\right)\right)+\Delta f_{i}\right] \\
\theta_{i} \text { is "high" if } g\left(r_{i}^{*}\right) \leq \gamma \theta_{i}\left[k\left(I_{i}\left(r_{j}^{*}\right)\right)+\Delta f_{i}\right]
\end{gathered}
$$

The interpretation of these definitions is as follows. When $\theta_{i}$ is low, manager $i$ wishes to rent-seek no matter what - even if he conjectures that, absent rent-seeking, he will be allocated the efficient level of investment $I_{i}^{*}$. In contrast, when $\theta_{i}$ is high, manager $i$ never rent-seeks, even if he conjectures that, absent rent-seeking, the capital budget will be tilted to manager $j$, so that he (manager $i$ ) gets a reduced allocation of only $I_{i}\left(r_{j}^{*}\right)$. Finally, when $\theta_{i}$ is medium, we have a case where there is the potential for strategic interaction: manager $i$ 's rent-seeking decision depends on his conjecture about how much capital he gets if he does not rent-seek.

With the definitions in hand, we can now provide a characterization of the solution to the CEO's problem. The full details are in Appendix A. Here we just state the main qualitative results:

Proposition 1: Assume without loss of generality that $\theta_{1}<\theta_{2}$. There are five regions to be considered:

1. Region 1: $\theta_{1}$ high or medium; $\theta_{2}$ high. In this region, neither division manager rent-seeks, and investment is efficient: $I_{i}=I_{i}^{*}$.

2. Region 2: $\theta_{1}$ low; $\theta_{2}$ high. In this region, only the manager of division 1 rent-seeks, and investment is distorted towards division 1: $I_{1}>I_{1}^{*}$.

3. Region 3: $\theta_{1}$ low; $\theta_{2}$ low. In this region, both division managers rent-seek. However, investment is efficient: $I_{i}=I_{i}^{*}$. The retention constraints of both managers are met with cash wages: $w_{i}>0$. 
4. $\underline{\text { Region 4: }} \theta_{1}$ low; $\theta_{2}$ medium. In this region, both division managers rent-seek. Depending on parameter values, investment may or may not be distorted towards division 1: $I_{1} \geq I_{1}^{*}$.

5. Region 5: $\theta_{1}$ medium; $\theta_{2}$ medium. In this region, there are two possible equilibria, which we denote by Equilibrium 5a and Equilibrium 5b.

Equilibrium 5a: Neither division manager rent-seeks, and investment is efficient: $I_{i}=I_{i}^{*}$

Equilibrium 5b: Both division managers rent-seek. Depending on parameter values, investment may or may not be distorted towards division $1: I_{1} \geq I_{1}^{*}$.

Region 1, where both divisions are relatively high-productivity, represents the simplest and least interesting case. In this portion of the parameter space, both managers are so satisfied with the prescribed levels of capital allocation and would lose so much in time-1 private benefits that they are no threat to rent-seek, and hence the outcome is fully efficient, in terms of the allocation of both managerial effort and physical capital. Note that the CEO's ability to extract private benefits from the operating budget causes no distortions in this case, since outside investors can simply set $\bar{W}=0$, without worrying that this leads to any problems.

Region 2 gets to the heart of our idea. Here division 1 is low-productivity, so that its manager rent-seeks no matter what the manager of division 2 does. In contrast, division 2 is high-productivity, so that its manager never rent-seeks, and therefore has a slack retention constraint. In order to retain the manager of division 1, the CEO has two choices: she can pay him a cash wage, or she can tilt the capital budget in his direction. The former costs her dollar-for-dollar, while the latter initially does not. This is because the retention constraint for division 2 is slack, so the CEO can shift resources away from it without having to compensate its manager for the lost investment with a cash wage. Thus at least initially, the CEO only bears a second-order cost (proportional to $\phi$ ) of distorting the capital budget, and this is the preferred means of compensating division manager 1 . This logic is sufficient to establish that investment is distorted towards division 1. 
Notice that whenever a division manager's retention constraint is slack, his cash wages are zero. This is because the CEO sets wages as low as possible in this region, in order to minimize the division manager's rents. At first glance, this might lead one to doubt the model's relevance, since wages of literally zero are never observed. However, it is trivial to modify the model so that cash wages are strictly positive even when the retention constraint is slack. Suppose that division managers face an additional liquidity constraint, which requires them to earn cash wages of $L$ in order to eat - i.e., they cannot live on private benefits alone. Thus if cash wages are below $L$, no amount of capital expenditures in their division can compensate for this. ${ }^{28}$ Then, of course, the CEO has to pay the division manager cash wages of $L$ to meet this liquidity constraint. And it is possible that when this liquidity constraint is met, the retention constraint is slack. Thus everything is the same as before, except the minimal point at which wages can be set is $L$, not zero. This simple renormalization makes the model more realistic in terms of its literal implications for cash wages, without changing any of the fundamental logic.

Region 3 is interesting because it makes the point that our results on investment inefficiencies require more than just the existence of low $\theta$ 's and rent-seeking per se - they require a pronounced imbalance between the productivity of the two divisions. When both divisions are low-productivity, and therefore both face binding retention constraints, it does the CEO no good to shift capital from division 2 to division 1, because in so doing she lowers the utility of manager 2 by at least as much as she raises the utility of manager 1, and hence does not make it any cheaper for herself to retain both managers. Instead, the CEO optimally chooses to pay off both rent-seeking managers with cash. As an aside, this case also illustrates that investment inefficiencies do not necessarily follow simply from the assumption that the CEO can abuse the operating budget. In this case, with two weak divisions, the CEO does what investors would consider to be the right thing with the operating budget, and spends it not on herself, but rather to retain the division managers.

Region 4 represents an intermediate case between Region 2 and Region 3, and is consistent with the broad intuition that investment distortions are most likely to occur when there is an imbalance between the two divisions. Here division 1 is still low-productivity, 
but division 2 is medium-productivity. In this situation, both division managers rent-seek. The consequences for investment are less clear-cut. Depending on parameter values, we can either have an outcome where investment is tilted towards division 1 (as in Region 2) or one where investment is allocated efficiently (as in Region 3). ${ }^{29}$

Finally, Region 5 is where the potential for strategic complementarities comes into play. In this region, both divisions are of medium productivity, so that each division manager's rent-seeking decision depends on the other's. This implies that there can be two equilibria. ${ }^{30}$ The first, 5a, has the same properties as the equilibrium in Region 1: no rent-seeking, and efficient investment. The second, 5b, is like that in Region 4: both managers rent-seek, and investment may (though need not) be distorted towards division 1.

In comparing these two equilibria, one point to note is that equilibrium 5a is Paretosuperior. Clearly, the CEO (as well as outside investors) prefer the outcome with no rentseeking. Moreover, it is easy to see from definition (11) that the two division managers prefer this equilibrium also. That is, equilibrium 5b represents a "coordination failure" outcome where each division manager defensively rent-seeks only because he expects his counterpart to do the same, and where both wind up worse off as a result. The potential for a firm to get stuck in this sort of dysfunctional equilibrium, where division managers waste their time in a futile tug-of-war over the capital budget, strikes us as a particularly interesting feature of the model.

From an empirical perspective, however, the single clearest prediction that emerges from Proposition 1 is that investment is most likely to be tilted towards the weaker division in a firm when it is paired with a much stronger division, as in Region 2. When there are more modest differences in productivity (as in Regions 4 or 5) there may possibly be investment distortions, but the prediction is more ambiguous.

Although Proposition 1 tells us about the direction in which the capital budget is tilted, it need not imply economically large distortions relative to the benchmark of $I_{i}=I_{i}^{*}$. Indeed, Proposition 1 as stated even applies when there is no agency problem between the CEO and outside investors; as noted earlier, this just corresponds to a special case where we set $\phi=1$ in expression (8). Even a principal may be willing to tilt the capital budget 


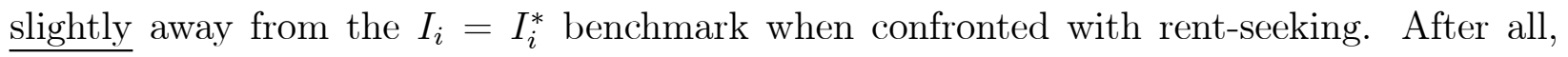
the principal's objective is not just to maximize investment output, but rather to maximize output less the cost of retaining rent-seeking managers. ${ }^{31}$

Of course, intuition suggests that while a principal might tilt the capital budget slightly, the quantitative effect should be much amplified when the decision is made by the CEO acting as an agent - i.e., when we have $\phi<<1$. Thus the natural next question to ask is: In those cases where investment is distorted, how big is the distortion? In Appendix A, we prove the following:

$\underline{\text { Proposition } 2}$ : Any time there is an investment distortion, the CEO shifts capital to division 1 until one of the following limits is hit:

1. Division manager 1's retention constraint is satisfied with a zero cash wage, i.e.: $I_{1}$ solves $g\left(r_{1}^{*}\right)=\gamma \theta_{1} k\left(I_{1}\right)$; or

2. The marginal cost to the CEO of distorting investment becomes so high that she is unwilling to distort it further, and prefers to pay the rest of the needed compensation to the manager of division 1 in cash: $\phi\left(\theta_{2} k^{\prime}\left(I_{2}\right)-\theta_{1} k^{\prime}\left(I_{1}\right)\right)=\gamma \theta_{1} k^{\prime}\left(I_{1}\right)$; or

3. The retention constraint of division manager 2 binds when $w_{2}=0: g\left(r_{2}^{*}\right)=$ $\gamma \theta_{2} k\left(I_{2}\right)$.

The implication of Proposition 2 is that we are likely to get a large distortion in investment allocation when the following conditions jointly obtain: i) division 1 is very weak, so that $\theta_{1}$ is very small and a large value of $I_{1}$ is needed to satisfy manager 1 's retention constraint; ii) division 2 is very strong, so that manager 2 never rent-seeks and always has a slack retention constraint; and iii) the CEO has low-powered incentives (i.e., $\phi$ is small) so that she is willing to tolerate a large difference in the marginal product of capital across the two divisions.

To isolate the pure effects of agency at the CEO level, note that from part 2 of Proposition 2, an upper bound on the investment distortion is given by $\theta_{2} k^{\prime}\left(I_{2}\right) / \theta_{1} k^{\prime}\left(I_{1}\right)=1+\gamma / \phi$. If $\phi$ and $\gamma$ are of the same order of magnitude, this implies a potentially large distortion. Now consider what happens if instead the CEO acts benevolently on behalf of outside investors, 
so that effectively, $\phi=1$. If we continue to maintain that $\gamma<<1$, it is easy to see that there can only ever be a very small deviation from the $I_{i}=I_{i}^{*}$ benchmark in this no-agency case. Thus to the extent that there are economically large deviations when $\phi<<1$, they are wholly attributable the CEO's weak incentives to maximize value.

Note that our results on distortions in capital expenditures are not critically dependent on the assumption that the CEO has all the bargaining power when making offers to the division managers at time 2. Rather, these distortions arise because of an externality. When the CEO and the division managers sit down to negotiate at time 2, outside investors are not at the table. Thus the CEO and division managers do not internalize the costs to these outside investors of misallocating the capital budget, and instead maximize only their own joint surplus. As a result, there is an incentive to distort the capital budget, regardless of how the resulting surplus is ultimately divided.

\section{Investors' Choice of $\bar{I}$ and $\bar{W}$}

To this point, we have been treating the amount of total firm-wide investment $\bar{I}$ as a fixed parameter. We have also been assuming that outside investors give the CEO an operating budget $\bar{W}$ that allows her to pay all cash wages she would like. The next step is to ask what values of $\bar{I}$ and $\bar{W}$ emerge from ex ante optimization on the part of outside investors.

Consider the optimal choice of $\bar{W}$ first. The method of analysis is as follows. First, solve the model - as we have above - under the assumption that the CEO is unconstrained with respect to setting cash wages. This implies an amount of cash that is needed to pay any $w_{1}$ or $w_{2}$. Now ask whether outside investors can gain by reducing $\bar{W}$ below $w_{1}+w_{2}$. (Clearly, they never wish to give the CEO more than this amount.)

Given the specific way we have modelled things, it is easy to show that investors never reduce $\bar{W}$ below $w_{1}+w_{2}$. For if they did, one of two things would have to happen: i) the CEO might distort the capital budget even further than before, so as to retain manager 1 without using any cash; or ii) the CEO would be simply unable to satisfy both managers' retention constraints - at least one manager would depart to his outside option. Under 
our assumptions, both of these outcomes are more costly to investors than the incremental savings in wages. Intuitively, the problem here is not with the cash wages that the CEO pays to division managers; rather it is the fact that the CEO would like to economize on cash wages, and hence prefers to use distortions in capital expenditures as a means of compensating division managers. Thus preventing the CEO from making those cash payments that she is actually willing to make can only worsen matters.

More generally, even if the model is changed so that it is in some circumstances optimal for investors to constrain the CEO's ability to pay cash wages, our results on investment distortions still go through - even more strongly and transparently so. To see this, suppose that we are in Region 2 of Proposition 1, where only the manager of the low- $\theta$ division rent-seeks. If the CEO does not have the cash to pay any wages, the only possible way for her to retain this manager is to tilt the capital budget in his favor.

The optimal choice of $\bar{I}$ is much less interesting for our purposes, in the sense that it does not interact in any meaningful way with any of our previous results. Everything that we have said thus far holds for any value of $\bar{I}$. Nonetheless, for completeness, it is worth discussing the determination of $\bar{I}$. If outside investors can count on there being no misallocations of the capital budget, they set $\bar{I}=I_{1}^{* *}+I_{2}^{* *}$, where $I_{i}^{* *}$ satisfies: $\theta_{i} k^{\prime}\left(I_{i}^{* *}\right)=1$. However, in those regions of the parameter space where they can anticipate misallocations, $\bar{I}$ is set at a lower value.

\section{Extensions and Variations}

\section{A. A Signal-Jamming Rationale for Conserving the Operating Budget}

Up to now, we have assumed that the auditing/verification technology is such that the CEO has some discretion over the operating budget - if the CEO does not spend the operating budget on division-manager wages, she can instead spend it on something else that raises her utility, such as excess travel. In contrast, the CEO has less discretion with respect to the capital budget - although she can choose in which division to spend it, the funds must be spent on physical capital somewhere in the firm, and cannot be used for other purposes. These assumptions taken together lead to our principal conclusion, namely that 
the CEO may prefer to tilt the capital budget rather than spend the operating budget to satisfy a division manager's demands.

Thus a natural criticism of our model is that our results are a by-product of an implausible assumption. Why, it might be asked, can't outside investors somehow circumscribe the CEO's ability to divert the operating budget? For example, with a stronger auditing technology, investors might be able to specify that the funds they put up for division-manager wages cannot be used for anything else. This would prevent the CEO from enjoying private benefits when she holds down division-manager wages.

In response to this critique, we should stress that it is not really necessary for our results that the CEO be able to divert the operating budget to herself. All that is really required is the much weaker condition that the $\mathrm{CEO}$ have some reason to care about economizing on wage payments to division managers. We now sketch one alternative model — without any diversion of the operating budget — which has this property.

The alternative model is a variation on Stein (1989). Assume that the CEO owns stock in the firm, and that she contemplates selling some of this stock in the not-too-distant future. Thus the CEO wishes to take actions that increase the short-run stock price, even if these actions ultimately reduce the firm's long-run value. At time 2, the CEO has ample cash on hand so that she can, if she chooses, pay any needed wages to the division managers. Any cash that is not spent on such wages is added to operating earnings, which are paid out in the form of a dividend to investors. So the CEO does not get to divert to herself any savings that are realized from holding down division-manager wages.

However, suppose that the division managers' equilibrium outside options — as given by $g\left(\hat{r}_{i}\right)$ - are observed only by the CEO, and not by investors. In this case, the CEO still has an incentive to skimp on cash wage payments to the division managers. For by doing so, she can boost reported earnings, and - to the extent that these earnings are informative about future prospects - raise the stock price.

Essentially, by making the outside options unobservable to investors, we have created a situation where reductions in cash wages are exactly analogous to Stein's (1989) notion of "borrowing" in an unobservable way against the future. In particular, investors now 
cannot tell whether a marginal increase in earnings comes from honestly good performance, or whether it reflects the fact that the CEO has held back on cash wages to the division managers (which is ultimately costly due to the resulting misallocation of capital). As a result, equilibrium necessarily involves some degree of this costly "borrowing", and our previous conclusions should continue to apply.

\section{B. Breakups}

To this point, we have simply assumed the existence of an integrated firm where the CEO has the authority to allocate the overall capital budget across the two divisions. But given the potential for inefficiencies that we have identified, it is natural to ask whether one can do better than in the integrated setting, by separating the two divisions. We cannot provide a complete answer to this question, because we have not modelled any of the potential benefits of integration, only the costs. But if one is willing to assume that the benefits are relatively constant across the parameter values of our model, we may have something to say about the circumstances under which a breakup is most likely to be a good idea. ${ }^{32}$

In the context of our model, a "breakup" can be conceptualized very simply, as follows. Divisions 1 and 2 are split into two distinct firms, each with their own CEOs, division managers, operating budgets, as well as capital budgets of $I_{i}^{* *}{ }^{33}$ It is easy to see that a breakup can be beneficial when we are in Region 2 of Proposition 1 - i.e., when the divisions are relatively unequal in strength and there is a distortion in investment in the integrated equilibrium. Upon breakup, this investment distortion is eliminated. Note however, that in this region a breakup does not eliminate the inefficient rent-seeking behavior on the part of the manager of the weak division. All it does is force the CEO to compensate the rent-seeking manager in cash, rather than with capital from the other division.

Somewhat more subtly, a breakup might also add value in Region 5, if the firm has somehow gotten stuck in the "bad" equilibrium 5b with rent-seeking. This holds true even if there is no investment distortion in equilibrium 5b. For when the divisions are separated, the multiplicity disappears and the unique outcome for these parameters is now one with no 
rent-seeking in either division. For similar reasons, a breakup can be helpful in Region 4 as well, regardless of whether or not there is an investment distortion in this region. ${ }^{34}$

In contrast, a breakup does no good if we are in Region 3, where both managers rentseek but there is no investment distortion. Post-breakup, there is still the same level of rent-seeking in each division, because, with low productivity, the incentive to rent-seek is so strong that any manager does so irrespective of his counterpart's behavior.

Thus the model is loosely suggestive about the circumstances under which one might expect to see breakups - they should be not so much driven by the absolute weakness of a given division, but rather by differences in productivity across multiple divisions in the same firm. Moreover, this thought experiment reinforces once again a point made earlier: the ability of the CEO to abuse the operating budget, taken by itself, need not lead to any inefficiencies. When there is a breakup, both CEOs spend any operating budgets efficiently, to retain their respective managers.

Of course, this whole line of reasoning is subject to the caveat that we have not endogenized the benefits of integration, and are implicitly treating them as a constant. To see why this simplification could be problematic, note that the beneficial, "winner-picking" aspects of an internal capital market might conceivably also be more pronounced when the divisions in question are more divergent in terms of productivity. ${ }^{35}$ If this is so, our predictions for breakups become less clear-cut.

\section{Empirical Implications}

A few recent empirical papers speak directly to our model's central predictions. Using segment-level data from COMPUSTAT, Shin and Stulz (1998) document that the investment of any given segment in a diversified firm depends on the cashflows of other, unrelated segments. Moreover, this apparent cross-subsidization "does not depend on whether that segment (receiving the transfer) has the best investment opportunities within the firm". (p. 533) As Shin and Stulz argue, this latter finding fits with our notion of socialism in internal capital markets.

Rajan, Servaes, and Zingales (2000) use a similar data set, and uncover three noteworthy patterns. First, consistent with the notion of socialism, multi-segment firms allocate 
relatively more than their stand-alone counterparts to segments in "weak" lines of business (as measured either by industry Q ratios or investment rates) and relatively less to segments in "strong" lines of business. Second, this misallocation of resources is most pronounced when there is a wide disparity in the productivity of investment across the lines of business, as proxied for by the dispersion of the corresponding industry $\mathrm{Q}$ ratios. This is directly in line with the predictions of our Propositions 1 and 2, which state that large investment inefficiencies are most likely to occur when there is a pronounced differential in divisions' investment opportunities. Finally, the investment distortions have significant value consequences - those diversified firms that have the most heterogeneous segments and that misallocate funds the most, also tend to trade at the largest discounts. ${ }^{36}$

Scharfstein (1998) also finds evidence of socialism in a sample of diversified conglomerates, in that the investment of conglomerate divisions is virtually insensitive to their investment opportunities, as measured by the corresponding industry Q's. (In contrast, the investment of stand-alone firms is significantly more sensitive to industry Q's.) But perhaps most interesting from the perspective of our model is Scharfstein's finding that socialism seems to be driven by a misalignment of incentives between outside investors and top management. In particular, he shows that the sensitivity of divisional investment to Q increases as top management's equity stake in the firm goes up. Or said differently, socialism is more pronounced when the CEO has low-powered incentives. This gets precisely at the heart of the most distinctive aspect of our model - the idea that the agency problem between the $\mathrm{CEO}$ and outside investors is a crucial part of the story. As noted earlier, the model of Rajan, Servaes, and Zingales (2000), where investment levels are set by a principal, rather than by an agent, does not make the same prediction.

Thus overall, evidence is beginning to emerge which suggests that not only is there a general tendency towards socialism in internal capital markets, but that this problem is more acute when: i) there are wide disparities across divisions in investment prospects; and ii) top management has weak incentives to maximize value. This broad picture squares very well with our theory. 


\section{Conclusions}

Although we have couched our model in terms of a CEO allocating capital to divisions, we believe it captures a more general and broadly applicable point about how organizations work. In its most basic form, our key insight is that when any agent $i$ inside an organization wishes to get any other agent $j$ to do something, she will likely try to pay for this not with cash, but rather by directing to agent $j$ an extra share of the resources over which she $(i)$ has allocative authority. Our model has considered an especially simple case where it is exogenously assumed that the CEO is the only one with any meaningful authority to allocate resources. But in reality, a wide range of agents throughout any organization have some authority to allocate resources, and non-monetary exchanges are pervasive.

Because these non-monetary exchanges are typically inefficient in our framework, a potentially important element of organizational design centers on how spreading or concentrating the power to make resource-allocation decisions affects efficiency. To see the sorts of issues that might arise, consider an example of a business school faculty that must make decisions in two different areas: i) it must choose which new faculty to recruit; and ii) it must assign existing faculty to teaching particular courses. Now compare two organizational design options. In the first case, a single individual is made department head and given the authority to make both decisions. In the latter, two separate people are put in charge of recruiting and course staffing.

On the one hand, the latter, two-headed option might well offer the advantage of specialized expertise in decision making - in other words, if somebody is responsible for just recruiting and nothing else, he is more likely to become more informed about the candidates. On the other hand, dividing up the authority in this way could conceivably increase the scope for inefficient "favor-trading." For example, the course-staffing chair might give a particularly light teaching load to the recruiting chair in exchange for being allowed to hire his favorite candidate. It might be interesting to model these sorts of trade-offs more explicitly, and to draw out their implications for organizational design. 


\section{Appendix A.}

Proof of Proposition 1: The optimal wage and capital budget at time 1 maximizes the CEO's utility:

$$
U \equiv \phi \theta_{1} k\left(I_{1}\right)-w_{1}+\phi \theta_{2} k\left(\bar{I}-I_{1}\right)-w_{2}
$$

subject to the retention constraints

$$
\begin{gathered}
w_{1}+\gamma \theta_{1} k\left(I_{1}\right) \geq g\left(r_{1}\right) \\
w_{2}+\gamma \theta_{2} k\left(\bar{I}-I_{1}\right) \geq g\left(r_{2}\right) .
\end{gathered}
$$

Note that we have made use of the fact that the capital budget is fixed so that $I_{1}+I_{2}=\bar{I}$.

The first-order conditions of the associated Lagrangian, $L$, of this constrained maximization are:

$$
\begin{gathered}
\frac{\partial L}{\partial w_{1}}=-1+\lambda_{1} \leq 0 \\
\frac{\partial L}{\partial w_{2}}=-1+\lambda_{2} \leq 0 \\
\frac{\partial L}{\partial I_{1}}=\phi\left[\theta_{1} k^{\prime}\left(I_{1}\right)-\theta_{2} k^{\prime}\left(\bar{I}-I_{1}\right)\right]+\lambda_{1} \gamma \theta_{1} k^{\prime}\left(I_{1}\right)-\lambda_{2} \gamma \theta_{2} k^{\prime}\left(\bar{I}-I_{1}\right)=0,
\end{gathered}
$$

where $\lambda_{1}$ and $\lambda_{2}$ are the Lagrange multipliers on the retention constraints. ${ }^{37}$

To establish the outcomes in the various regions, it is helpful to characterize $I_{2}\left(r_{1}^{*}\right)$, the investment allocation to Manager 2 (M2) when he does not rent-seek but Manager 1 (M1) does. In this case, M2 has no outside option so his retention constraint is never binding; $\lambda_{2}=0$. Therefore, the relevant first-order conditions are equation (A4) and a simplified version of equation (A6):

$$
\frac{\partial L}{\partial I_{1}}=\phi\left[\theta_{1} k^{\prime}\left(I_{1}\right)-\theta_{2} k^{\prime}\left(\bar{I}-I_{1}\right)\right]+\lambda_{1} \gamma \theta_{1} k^{\prime}\left(I_{1}\right)=0
$$

There are two mutually exclusive solutions in this case, which can only occur when $g\left(r_{1}^{*}\right)<\gamma \theta_{1} k\left(I_{1}^{*}\right)$. (Otherwise M1 would not rent-seek.)

(i) Define $I_{1}^{a}$ as the solution to the retention constraint when $w_{1}=0$ :

$$
\gamma \theta_{1} k\left(I_{1}^{a}\right)=g\left(r_{1}^{*}\right)
$$


At an optimum $w_{1}=0$ and $I_{1}=I_{1}^{a}$ provided,

$$
\frac{\partial L}{\partial I_{1}}=\phi\left[\theta_{1} k^{\prime}\left(I_{1}^{a}\right)-\theta_{2} k^{\prime}\left(\bar{I}-I_{1}^{a}\right)\right]+\gamma \theta_{1} k^{\prime}\left(I_{1}^{a}\right)>0 .
$$

Given equation (A9), there exists a $\lambda_{1}<1$ such that the first-order condition (A7) is satisfied for $I_{1}^{a}>I_{1}^{*}$. Intuitively, at $I_{1}=I_{1}^{a}$, the marginal reduction in M1's wage made possible by an increase in $I_{1}, \gamma \theta_{1} k^{\prime}\left(I_{1}^{a}\right)$, exceeds the marginal cost to the principal of distorting investment, $\quad \phi\left[\theta_{2} k^{\prime}\left(I-I_{1}^{a}\right)-\theta_{1} k^{\prime}\left(I_{1}^{a}\right)\right]$.

(ii) If equation (A9) is not satisfied then $I_{1}$ must be less than $I_{1}^{a}$ for the first-order condition (A7) to be satisfied. Thus, $w_{1}>0$ if the retention constraint is to be satisfied, from which it follows that $\lambda_{1}=1$. At an optimum $I_{1}=I_{1}^{b}$ where $I_{1}^{b}$ solves:

$$
\phi\left[\theta_{1} k^{\prime}\left(I_{1}^{b}\right)-\theta_{2} k^{\prime}\left(\bar{I}-I_{1}^{b}\right)\right]+\gamma \theta_{1} k^{\prime}\left(I_{1}^{b}\right)=0
$$

Note that $I_{1}^{a}>I_{1}^{b}>I_{1}^{*}$. The important point is that $I_{2}\left(r_{1}^{*}\right)<I_{2}^{*}$ when $\gamma \theta_{1} k\left(I_{1}^{*}\right)<g\left(r_{1}^{*}\right)$; M2 gets less than the efficient allocation of capital if he does not rent-seek but M1 does.

We now show that the equilibrium outcomes correspond to the five regions described in the Proposition.

$\underline{\text { Region 1: }} \theta_{1}$ high or medium; $\theta_{2}$ high. In this region, M2 does not rent-seek regardless of what M1 does; it is a dominant strategy for M2 not to rent-seek. To see this, suppose M1 rent-seeks. If M2 also rent-seeks he receives $g\left(r_{2}^{*}\right)$ at date 2 but loses $\gamma \theta_{2} \Delta f_{2}$ at date 1 . If M2 does not rent-seek, he gets $\gamma \theta_{2} k\left(I_{2}\left(r_{1}^{*}\right)\right)$ as shown above. This establishes that M2 does not rent-seek when $g\left(r_{2}^{*}\right) \leq \gamma \theta_{2}\left[k\left(I_{2}\left(r_{1}^{*}\right)\right)+\Delta f_{2}\right]$, which is satisfied by the definition of $\theta_{2}$ being high. If M1 does not rent-seek, then M2 has even less incentive to rent-seek, since when neither manager rent-seeks, the allocation of capital is efficient. So M2 does not rent-seek provided $g\left(r_{2}^{*}\right) \leq \gamma \theta_{2}\left[k\left(I_{2}^{*}\right)+\Delta f_{2}\right]$. Given that $I_{2}\left(r_{1}^{*}\right)<I_{2}^{*}$ the condition defining this region again implies that M2 does not rent-seek.

Since M2 does not rent-seek, it is straightforward to show that M1 does not rent-seek provided $g\left(r_{1}^{*}\right) \leq \gamma \theta_{1}\left[k\left(I_{1}^{*}\right)+\Delta f_{1}\right]$ which is satisfied for $\theta_{1}$ high or medium. Thus, neither 
manager rent-seeks, neither retention constraint is binding, and the allocation of capital is efficient.

Region 2: $\theta_{1}$ low; $\theta_{2}$ high. As shown above, if $\theta_{2}$ is high, it is a dominant strategy for M2 not to rent-seek. However, M1 rent-seeks because when $\theta_{1}$ is low $g\left(r_{1}^{*}\right)>\gamma \theta_{1}\left[k\left(I_{1}^{*}\right)+\Delta f_{1}\right]$. We have already shown that if M1 rent-seeks and M2 does not, $I_{1}=\bar{I}-I_{2}\left(r_{1}^{*}\right)>I_{1}^{*}$.

Region 3: $\theta_{1}$ low; $\theta_{2}$ low. First we show that it is a Nash equilibrium for both managers to rent-seek in this region. If M2 does not rent-seek but M1 does, he receives $I_{2}\left(r_{1}^{*}\right)$ in capital, where we know that $I_{2}\left(r_{1}^{*}\right)<I_{2}^{*}$. Thus, $g\left(r_{2}^{*}\right)>\gamma \theta_{2}\left[k\left(I_{2}\left(r_{1}^{*}\right)+\Delta f_{2}\right]\right.$ because we have assumed that in this region $g\left(r_{2}^{*}\right)>\gamma \theta_{2}\left[k\left(I_{2}^{*}\right)+\Delta f_{2}\right]$. An analogous argument establishes that M1 rent-seeks given that M2 rent-seeks.

We now show that the investment allocation is efficient in this region. First, note that both wages must be strictly positive. If neither wage were positive both retention constraints could not be met. If $w_{1}>0$ but $w_{2}=0$, then $I_{2}>I_{2}^{*}$. In this case, the first-order condition (A6) implies $\lambda_{2}>\lambda_{1}$. But since $w_{1}>0, \lambda_{1}$ must equal 1 and $\lambda_{2}$ cannot be greater than 1 from the first-order condition (A4). Thus, $w_{1}>0, w_{2}=0$ is not an optimal solution. An analogous argument establishes that $w_{1}=0, w_{2}>0$, is also not optimal. It follows that $w_{1}>0$ and $w_{2}>0$ and that equations (A4) and (A5) therefore imply $\lambda_{1}=\lambda_{2}=1$. Substituting into condition (A6) implies that $I_{i}=I_{i}^{*}$ at an optimum.

Region 4: $\theta_{1}$ low; $\theta_{2}$ medium. The discussion of Region 3 establishes that if $g\left(r_{2}^{*}\right)>$ $\gamma \theta_{2}\left[k\left(I_{2}\left(r_{1}^{*}\right)\right)+\Delta f_{2}\right]$, M2 rent-seeks if M1 does. And, given that M2 rent-seeks, M1 rent seeks if $g\left(r_{1}^{*}\right)>\gamma \theta_{1}\left[k\left(I_{1}\left(r_{2}^{*}\right)\right)+\Delta f_{1}\right]$ where $I_{1}\left(r_{2}^{*}\right)$ is the investment allocation to M1 when M1 does not rent-seek but M2 does. Since $\theta_{1}$ being low means $g\left(r_{1}^{*}\right)>\gamma \theta_{1}\left[k\left(I_{1}^{*}\right)+\Delta f_{1}\right]$ and $k\left(I_{1}^{*}\right)>k\left(I_{1}\left(r_{2}^{*}\right)\right)$, the rent-seeking condition is met and M1 also rent-seeks.

While both managers rent-seek, the investment allocation may or may not be efficient. It is efficient if $\gamma \theta_{2} k\left(I_{2}^{*}\right)<g\left(r_{2}^{*}\right)$. In this case the argument for the efficiency of the investment allocation in Region 3 goes through unaltered. However, if $g\left(r_{2}^{*}\right)<\gamma \theta_{2} k\left(I_{2}^{*}\right)$, then it is possible for the investment allocation to be inefficient. Let $I_{2}^{c}$ be the investment level such that: 


$$
g\left(r_{2}^{*}\right)=\gamma \theta_{2} k\left(I_{2}^{c}\right) .
$$

Recall that $I_{1}^{a}$ and $I_{1}^{b}$ are the possible optimal investment allocations when M2's retention constraint is not binding. If $\bar{I}-I_{1}^{a}>I_{2}^{c}$ or $\bar{I}-I_{1}^{b}>I_{2}^{c}$, then one of these (either $I_{1}^{a}$ or $I_{1}^{b}$ ) is the solution, because M2's constraint is not binding at these levels. If this is not the case, then another possible solution is to set $w_{2}=0$ and $I_{2}=I_{2}^{c}$. This is the solution if

$$
\phi\left[\theta_{1} k^{\prime}\left(\bar{I}-I_{2}^{c}\right)-\theta_{2} k^{\prime}\left(\bar{I}_{2}^{c}\right)\right]+\gamma \theta_{1} k^{\prime}\left(\bar{I}-I_{2}^{c}\right)>0 .
$$

One can verify that in this case $w_{1}>0, \lambda_{1}=1,0<\lambda_{2}<1$ satisfies all the first-order conditions for an optimum. This suffices to show that the investment allocation can also be inefficient in Region 4.

$\underline{\text { Region 5: }} \theta_{1}$ medium; $\theta_{2}$ medium.

Equilibrium 5a: In this equilibrium neither manager rent-seeks. Given that $M_{j}$ does not rent-seek, $M_{i}$ does not rent-seek because in this region $g\left(r_{i}^{*}\right) \leq \gamma \theta_{i}\left[k\left(I_{i}^{*}\right)+\Delta f_{i}\right]$. If neither manager rent-seeks then neither retention constraint is binding, and the investment allocation is efficient.

Equilibrium 5b: In this equilibrium both managers rent-seek. The condition for $i$ to rent-seek given that $j$ rent-seeks is $g\left(r_{i}^{*}\right)>\gamma \theta_{i}\left[k\left(I_{i}\left(r_{j}^{*}\right)+\Delta f_{i}\right]\right.$ which is satisfied when $\theta_{i}$ is medium. A similar argument to the one for Region 4 establishes that the investment allocation may or may not be efficient.

Proof of Proposition 2: We have already established Proposition 2 in the course of proving Proposition 1. In particular, the three different possible outcomes where $I_{1}>I_{1}^{*}$ referred to in Proposition 2 correspond to $I_{1}^{a}, I_{1}^{b}$, and $I_{1}^{c}$, as defined in equations (A8), (A10) and (A11) respectively. 


\section{References}

Aghion, Philippe, and Jean Tirole, 1997, Formal and real authority in organizations, Journal of Political Economy 105, 1-29.

Bagwell, Laurie Simon, and Josef Zechner, 1993, Influence costs and capital structure, Journal of Finance 48, 975-1008.

Berger, Philip, and Eli Ofek, 1995, Diversification's effect on firm value, Journal of Financial Economics 37, 39-65.

Berger, Philip, and Eli Ofek, Bustup takeovers of value-destroying diversified firms, Journal of Finance 51, 1175-1200.

Bhagat, Sanjai, Andrei Shleifer, and Robert W. Vishny, 1990, Hostile takeovers in the 1980s: The return to corporate specialization, Brookings Papers on Economic Activity: Microeconomics Special Issue, 1-72.

Bolton, Patrick, and David Scharfstein, 1990, A theory of predation based on agency problems in financial Contracting, American Economic Review 80, 94-106.

Burkart, Mike, Denis Gromb, and Fausto Panunzi, 1997, Large shareholders, monitoring, and the value of the firm, Quarterly Journal of Economics 112, 693-728.

Comment, Robert, and Gregg A. Jarrell, 1995, Corporate focus and stock returns, Journal of Financial Economics 37, 67-87.

Edlin, Aaron S., and Joseph E. Stiglitz, 1995, Discouraging rivals: managerial rent seeking and economic inefficiencies, American Economic Review 85, 1301-1312.

Fauver, Larry, Joel Houston, and Andy Naranjo, 1998, Capital market development, legal systems and the value of corporate diversification: A cross-country analysis, Working paper, University of Florida.

Fulghieri, Paolo, and Laurie Simon Hodrick, 1997, Synergies and internal agency conflicts: The double-edged sword of mergers, Working paper, Columbia University.

Grossman, Sanford, and Oliver Hart, 1986, The costs and benefits of ownership: A theory of vertical and lateral integration., Journal of Political Economy 94, 691-719. 
Hart, Oliver, and John Moore, 1990, Property rights and the nature of the firm, Journal of Political Economy 98, 1119-58.

Hart, Oliver, and John Moore, 1998, Default and renegotiation: A dynamic model of debt, Quarterly Journal of Economics 113, 1-41.

Holmström, Bengt, and Paul Milgrom, 1990, Regulating trade among agents, Journal of Institutional and Theoretical Economics 146, 85-105.

Jensen, Michael C., 1986, Agency costs of free cash flow, corporate finance and takeovers, American Economic Review 76, 323-329.

Jensen, Michael C., 1993, The modern industrial revolution, exit, and the failure of internal control systems, Journal of Finance 48, 831-880.

Lamont, Owen, 1997, Cash flow and investment: evidence from internal capital markets, Journal of Finance 52, 83-109.

Lang, Larry H.P., and René Stulz, 1994, Tobin's q, corporate diversification, and firm performance, Journal of Political Economy 102, 1248-1280.

Lins, Karl, and Henri Servaes, 1999, International evidence on the value of corporate diversification, Journal of Finance 54, forthcoming.

Matsusaka, John, and Vikram Nanda, 1997, Internal capital markets and corporate refocusing, Working Paper.

McAfee, R. Preston, and John McMillan, 1995, Organizational diseconomies of scale, Journal of Economics and Management Strategy 4, 399-426.

Meyer, Margaret, Paul Milgrom, and John Roberts, 1992, Organizational prospects, influence costs, and ownership changes, Journal of Economics and Management Strategy 1, 9-35.

Prendergast, Canice, and Lars Stole, 1996, Non-monetary exchange within firms and industries, NBER Working Paper No. 5765.

Rajan, Raghuram G., Henri Servaes, and Luigi Zingales, 2000, The cost of diversity: The diversification discount and inefficient investment, Journal of Finance, forthcoming.

Rotemberg, Julio, 1993, Power in profit-maximizing organizations, Journal of Economics and Management Strategy 2, 165-198.

Scharfstein, David, 1998, The dark side of internal capital marketsII: Evidence from diver- 
sified conglomerates, NBER Working Paper No. 6352.

Shin, Hyun-Han, and René Stulz, 1998, Are internal capital markets efficient? Quarterly Journal of Economics 113, 531-552.

Shleifer, Andrei, and Robert W. Vishny, 1989, Management entrenchment: The case of manager-specific iInvestments, Journal of Financial Economics 25, 123-140.

Stein, Jeremy C., 1989, Efficient capital markets, inefficient firms: A model of myopic corporate behavior, Quarterly Journal of Economics 104, 655-669.

Stein, Jeremy C., 1997, Internal capital markets and the competition for corporate resources, Journal of Finance 52 11-134.

Tirole, Jean, 1986, Hierarchies and bureaucracies, Journal of Law, Economics and Organization 2, 181-214.

Williamson, Oliver E., 1975, Markets and Hierarchies: Analysis and Antitrust Implications (Collier Macmillan Publishers, Inc., New York).

Wulf, Julie, 1997, Influence and inefficiency in the internal capital market: Theory and evidence, Working paper, Columbia University. 


\section{Notes}

${ }^{1}$ See, e.g., Lang and Stulz (1994), Berger and Ofek (1995), and Comment and Jarrell (1995) for evidence from the U.S., and Lins and Servaes (1999) and Fauver, Houston, and Naranjo (1998) for international evidence.

${ }^{2}$ See Bhagat, Shleifer, and Vishny (1990) and Berger and Ofek (1996).

${ }^{3}$ This might occur, if, for example, coinsurance effects allow a conglomerate to borrow more against its assets than a comparable portfolio of specialized firms. However, recent empirical work by Berger and Ofek (1995) finds that in practice, this extra-borrowing effect is of trivial importance.

${ }^{4}$ See Lamont (1997), Shin and Stulz (1998).

${ }^{5}$ See also Matsusaka and Nanda (1997) for a similar argument about the potential benefits of an internal capital market.

${ }^{6}$ On a related note, Shleifer and Vishny (1989) argue that CEOs will prefer to invest in industries where they have more personal experience, as this makes them indispensable.

${ }^{7} \mathrm{~A}$ few recent papers have begun to provide empirical support for these claims. We discuss these papers in some detail in Section IV.B below.

${ }^{8}$ In Meyer, Milgrom and Roberts (1992), there are no investment inefficiencies. The only distortions are the time and effort expended by managers in a fruitless attempt to convince headquarters not to shrink their divisions.

${ }^{9}$ Tirole (1986) is one of the first papers to explicitly analyze a multi-layer agency problem. However, he does not consider the possibility that agents could be compensated in a form other than cash. See also Holmstrom and Milgrom (1990) and McAfee and McMillan (1995) 
for related work on multi-layer agency issues.

${ }^{10}$ See also Prendergast and Stole (1996) who provide a number of other reasons why intrafirm transactions might optimally be done in a non-monetary fashion.

${ }^{11}$ Wulf (1997) also argues that a principal might optimally choose tilt the capital budget so as to mitigate an agency problem with divisional managers.

${ }^{12}$ Examples of such models include Bolton and Scharfstein (1990) and Hart and Moore (1998).

${ }^{13}$ See also Shleifer and Vishny (1989), Bagwell and Zechner (1993), Edlin and Stiglitz (1995), and Fulghieri and Hodrick (1997) for similar interpretations of rent-seeking inside firms.

${ }^{14}$ The reason that resumé-polishing is easier to work with is that one can endow the CEO with all the bargaining power at time 2 - so that division managers are held to just their outside options - and still get non-zero rent-seeking. In contrast, with the entrenchment formulation, division managers only rent-seek if they get to share the surplus with the CEO. Given that our game has three players (the two division managers and the CEO) solving the model with surplus-sharing becomes somewhat complicated.

${ }^{15} \mathrm{~A}$ natural extension of the model is to allow a division manager's outside option to depend not only on his level of rent-seeking, but also on the productivity of the industry in which he specializes - e.g. one might write the outside option as $\left(1+\delta \theta_{i}\right) g\left(r_{i}\right)$ for some $\delta>0$. So long as $\delta$ is not too large, our basic results about there being more rent-seeking problems in weak (low- $\theta$ ) divisions continue to apply. This becomes clear as we develop the model further.

${ }^{16}$ To the extent that $\phi$ is "small", this assumption implies that the degree of entrenchment 
$X$ is economically significant.

${ }^{17}$ We should be a bit careful with the use of the term "efficient" here. As we see below, under certain conditions, even outside investors might wish to deviate slightly from the benchmark where $I_{i}=I_{i}^{*}$.

${ }^{18}$ It is not necessary for a court to be able to verify capital expenditures at the divisional level. One can imagine that at time 2, the CEO first irreversibly sinks the capital allocations, and then conditional on these allocations, promises to pay any still-needed cash wage to each division manager if he stays on.

${ }^{19}$ By using a strict inequality, we are implicitly assuming that if the division manager is indifferent, he does not rent-seek.

${ }^{20}$ None of this implies that low- $\theta$ managers get higher total utility than high- $\theta$ managers. Even without a cash wage, high- $\theta$ managers can be very well off because they get more investment and higher private benefits.

${ }^{21}$ Again, it is worth noting the contrast with models such as Hart and Moore (1998) and Bolton and Scharfstein (1990), where managers can steal all the cashflow from physical assets.

${ }^{22}$ Implicit in this definition is the idea that a court cannot enforce a contract that specifies investment at the divisional level, perhaps because it cannot verify unambiguously which division "owns" a given piece of capital.

${ }^{23}$ One reason that integration might be ex-ante beneficial-and that investors might be willing to tolerate some ex-post inefficiencies-is that the CEO has better information about divisional investment opportunities than do outside investors. See Stein (1997) for a rationale along these lines. 
${ }^{24}$ An essentially identical assumption is made by McAfee and McMillan (1995) in their analysis of a multi-tier hierarchy: the "top principal" is assumed to be unable to contract directly with the agent. They argue that this constraint reflects limits on the top principal's time and attention. (p.407)

${ }^{25}$ This line of argument follows Aghion and Tirole (1997) and Burkart, Gromb and Panunzi (1997) in emphasizing that the CEO may have de facto authority with respect to certain decisions, even if outside investors are endowed with formal control rights in the sense of Grossman and Hart (1986) and Hart and Moore (1990).

${ }^{26}$ Note the key contracting assumption that we have slipped in with this metaphor. We are implicitly assuming that while outside investors can control the firm's aggregate operating budget, they cannot control it line-by-line. In particular, the auditing/verification technology does not allow outside investors to stipulate: "These funds can be used to pay divisionmanager wages, but they cannot be used for travel expenses."

${ }^{27}$ Note that we have guaranteed that the CEO always wishes to satisfy the retention constraints by virtue of our earlier assumption that $\phi X>g\left(r_{i}\right)$.

${ }^{28}$ In other words, when cash wages are below $L$, there is no susbstitutability between cash and capital expenditures in the division manager's utility function. Above $L$, they are perfectly susbstitutable, as in our current formulation.

${ }^{29}$ In the latter case of efficient investment, both retention constraints are met with cash wages, also as in Region 3.

${ }^{30}$ Although the models are quite different, our multiple-equilibrium result is similar in spirit to Proposition 3 of Fulghieri and Hodrick (1997).

${ }^{31}$ When one division manager's retention constraint is slack, and the principal initially 
shifts a little bit of capital to another manager with a binding constraint, he suffers only a second-order investment inefficiency but realizes a first-order savings in cash wages.

${ }^{32}$ When we say "good idea" this is from the perspective of outside investors. In reality, of course, good ideas of this kind may not be implemented right away if the CEO enjoys having a large empire and is insulated from shareholder pressure, so large investment inefficiencies may persist for long periods of time.

${ }^{33}$ Note that in our setting, a CEO is still required for each division operating as a standalone, because it is the CEO who identifies and hires the division manager.

${ }^{34}$ When a medium-productivity division is separated from a low-productivity division, its optimal strategy shifts from rent-seeking to not rent-seeking. This is an efficiency gain above and beyond any investment effect.

${ }^{35}$ However, Stein (1997) argues that "winner-picking" may actually work better when the divisions are in related lines of business.

${ }^{36}$ Berger and Ofek (1995) also find that the conglomerate discount is greatest in firms that invest the most in low- $Q$ lines of business.

${ }^{37}$ The assumption that $k^{\prime}(0)=\infty$ guarantees that $I_{1}>0$ and $\frac{\partial L}{\partial I_{1}}=0$ at an optimum. 